\title{
INTERNATIONAL MIGRATION

\section{Shocks and spatial regime fades in Spain's international migration distribution}

\begin{tabular}{|r|l|}
\hline Journal: & International Migration \\
\hline Manuscript ID & IM-15-132.R1 \\
\hline Manuscript Type: & Original Article \\
\hline Keywords: & international migration, Spain, spMorph algorithm, space-time analysis \\
\hline Abstract: & $\begin{array}{l}\text { Using an exploratory space-time analysis called spMorph, this paper } \\
\text { explores how the spatial distribution of international migration across the } \\
\text { Spanish provinces has evolved over the period of 1998-2010. The chief } \\
\text { advantage of this approach is that it permits the unambiguous } \\
\text { identification of two key components in a spatial redistribution process, } \\
\text { namely the shocks on the spatial distribution and the duration of the } \\
\text { regime fades. The results of the analysis show that administrative regions } \\
\text { do not provide a reliable picture of the real dynamics in Spain's } \\
\text { international migration distribution. In addition, the identification of two } \\
\text { spatial shocks reveals the existence of three spatial regimes that } \\
\text { consistently characterize the various phases that international migration } \\
\text { has been through since the late 1990s. }\end{array}$ \\
\hline
\end{tabular}




\title{
Shocks and spatial regime fades in Spain's international migration
}

\section{distribution}

\begin{abstract}
Using an exploratory space-time analysis called spMorph, this paper explores how the spatial distribution of international migration across the Spanish provinces has evolved over the period of 1998-2010. The chief advantage of this approach is that it permits the unambiguous identification of two key components in a spatial redistribution process, namely the shocks on the spatial distribution and the duration of the regime fades. The results of the analysis show that administrative regions do not provide a reliable picture of the real dynamics in Spain's international migration distribution. In addition, the identification of two spatial shocks reveals the existence of three spatial regimes that consistently characterize the various phases that international migration has been through since the late 1990s.
\end{abstract}

Keywords: space-time analysis, spMorph algorithm, international migration, Spain. 


\section{Shocks and spatial regime fades in Spain's international migration distribution}

\section{Introduction}

Over the past nearly decade and a half the issue of international migration to Spain has risen to the forefront of academic and policy discussions. With immigration to Western and Northern Europe becoming more restrictive, as other Southern European countries Spain emerged as a major destination of immigration to the point of evolving from a country of emigration (e.g. Izquierdo, 1996; Arango, 2003) to one of the major immigration countries in Europe (Carling, 2007; Peixoto et al., 2012; Hierro, 2016). Factors contributing to it include lower differences between the South and the North of Europe concerning wages and living standards, a strong demand for immigrant workers (specially in the construction, agriculture and service sectors), less restrictive migration policies, economic prosperity and political stability (Huntoon, 1998; Carella and Pace, 2001; Hierro, 2016).

By the late 1990s, with immigration starting to increase fuelled by the take-off of the Spanish economy, international migration was believed to be a major factor in resolving labor and demographic challenges and to restore the long-term sustainability of the social protection system. This view started to change a few years later when the wave of immigration exceeded all predictions and the percentage of immigrants in the total Spanish population accelerated (from $1.6 \%$ in 1998 to $10 \%$ in 2007). Then started what has been coined as a "prodigious decade" of immigration in Spain (Finotelli and Arango, 2011). Subsequent to the onset of the recent economic crisis in 2008, albeit no sudden drop in the stock of immigrants in Spain was observed, immigration growth seemed to come to a halt (the percentage of immigrant population in Spain increased from 11.4\% in 2008 to only 12.2\% in 2010). Although the end of the period of massive immigration to Spain seems widely accepted (Reher et al., 2011), issues related to international migration are still open to active investigation. 
The mobility and locational choices of immigrants, the reasons behind their arrival and their socio-economic and demographic effects on the Spanish society have been issues specifically analyzed in a number of studies (e.g. Bover and Velilla, 2002; Recaño, 2002; Arango, 2003; Izquierdo and Carrasco, 2005; Recaño y Domingo, 2006; Fernández and Ortega, 2008; Dall'erba and Guo, 2009; Reher and Silvestre, 2009; Hierro and Maza, 2010a, b; Maza et al., 2013; Hierro et al., 2013; Neubecker and Smolka, 2013; Collantes et al. 2014; Reher and Silvestre, 2014). With regard to locational choices, since the pioneering work by Recaño (2002) on the demographic characteristics and the spatial patterns of the foreign internal migration in Spain, the literature on the spatial distribution of the immigrant population, albeit not very prolific, has attracted the attention of academics and researchers alike.

This study is an attempt to contribute to a better understanding of the changes that have occurred in the spatial distribution of Spain's international migration over time as we consider it deserves to be looked at more closely for a number of reasons. First, there are many important yet hitherto unexplored issues connected to both spatial and temporal perspectives of international migration. Second, the impact of international migration on various Spanish provinces merits a careful examination and assessment. This is not a minor question because it may entail serious differences across provinces that are related to labor market competition and public burden. Third, the common problem of spatial aggregation bias when considering official or administrative areas deserves special attention on the grounds of international migration because this can induce lower levels of policy effectiveness. In this regard, the paper tries to respond to the call for more research in the area of space-time clustering made by Duque et al. (2014) and by Hierro et al. (2013) in the field of international migration.

Thus, the aim of this paper is to conduct an exploratory space-time analysis of the international migration distribution in Spain. For this, we resort to a novel space-time clustering approach 
introduced by Duque et al. (2014) called spMorph. This algorithm can be considered a prominent contribution to this field of research because it allows for the aggregation of spatially contiguous areas into analytical regions such that the areas within them show similar behavior in terms of the variable under study and provides the possibility of splitting the sample period into sub-periods characterized by various economic regimes. The basis of this approach lies in the well-known ecological fallacy that establishes that conclusions for predefined official regions (namely, normative or administrative regions) do not always reflect the reality of the individuals who belong to these regions (Duque et al., 2006), and spatial aggregations in transitional economic systems are expected to be unstable over time due to shocks or regime switches. The application of this approach seems to be promising for examining a phenomenon such as international migration, which is highly exposed to spatial dependence effects as noted by Hierro et al. (2013) and to the emergence of various transitional regimes that pertain to various waves of immigration and higher ethnic diversity.

To conduct the study, we use annual data on the officially registered foreign-born population ${ }^{1}$ for the period of 1998-2010. These data are provided by the Spanish National Statistics Institute (INE) and are taken from the so-called "Municipal Register" (Padrón Municipal de Habitantes). This dataset provides information on the immigrant stock already settled in Spain and inscribed in a municipal register so that no distinction is made between newcomers and the internal mobility of immigrants already settled in the country. There are at least two reasons for the choice of this dataset. The first and most important is that, along with its ever-growing quality and coverage, the data are annual, which makes a thorough dynamic analysis of the distribution possible. The other relevant reason is that this dataset encompasses both regular and irregular foreign-born populations, which represents a clear advantage over other datasets because

\footnotetext{
${ }^{1}$ In this paper international migration stocks residing in a country are selected, as stocks are less volatile than inflows. Notwithstanding this, and not denying the distinction between "immigration" (migration inflow) and "foreign-born population" (migration stock), both terms are used synonymously in this paper.
} 
irregular immigration is not usually collected by official statistics. ${ }^{2}$ As for the level of territorial disaggregation, the study comprises the Spanish provinces that correspond to the Nomenclature of the Territorial Units for Statistics (NUTS) level 3. We excluded Canary and Balearic Islands from the study because the spMorph requires the areas of analysis to be spatially connected in order to apply spatially constrained clustering algorithms. Including these islands would require making artificial connections between the islands and the peninsula that would be difficult to argue.

The remainder of the paper is as follows. In Section 2, we discuss briefly Spain's recent experience of international migration. In Section 3, we present the main features of the spMorph algorithm. In Section 4, we explore the spatiotemporal dynamics of Spain's international migration distribution by means of the spMorph. Finally, Section 5 concludes the paper and provides some directions for future research.

\section{International migration in Spain: an overview}

International migration has been a heated policy discussion topic in the European Union (EU) in recent decades and especially since the late 1990s. This is because migratory flows in Europe have dramatically grown both in scale and complexity. Foremost among these changes is the transition of most Southern European countries from being the sources of immigrants to being the main recipients of international migrants and the upsurge of significant migration flows from Eastern to Western Europe, which largely involves refugees and asylum seekers fleeing

\footnotetext{
${ }^{2}$ Following the extension of some social rights to immigrants by the Ley Orgánica 4/2000 and particularly the provision of health assistance to undocumented immigrants registered in a Municipal Register, a large number of undocumented immigrants who reside in Spain has become "visible," which yields a more precise count of the international migration numbers through this official statistic. In addition, since December 2003, the obligation of non-EU foreign-born residents without a permanent legal permit to renew their registration in the municipal registry every two years might have contributed to improve the reliability of the statistic (Peixoto et al., 2012).
} 
poverty and conflict following the collapse of communist regimes in Eastern Europe. As far as this issue is concerned, Spain is by far the Southern European country where international migration has increased at the most impressive pace due to massive immigration, which largely comes from Eastern Europe, Latin America and North Africa (Peixoto et al., 2012; Hierro, 2016).

Figure 1 reports the evolution of the foreign-born population in Spain between 1998 and 2010 (in absolute numbers and as percentage of total population). According to this figure, the foreign-born population increased strongly from 637 to 5,747 thousand persons annually. This increase was especially marked between 2001 and 2004 and between 2007 and 2008; this resulted from large migration inflows that came from South America (mainly Ecuador and Colombia) benefited from visa-free entry into Spain, the decision of the EU to lift visa requirement for Romanians travelling within the Schengen Area in 2002, and large inflows from Romania after its entry into the EU. It is also worth noting that immigrants share in the total population experienced an even more impressive growth from $1.6 \%$ in 1998 to $12.2 \%$ in 2010 . There are sound reasons for the extremely large increase in international migration in Spain; among these, it is worth mentioning the following: the economic opportunities derived from Spain's entry into the European Community in 1986; the vigorous economic growth experienced during the late 1990s and early 2000s; a rather lenient immigration policy; a high demand for migrant labor in low-skilled and low-paid activities (largely agriculture, construction and traditional services sectors); a reduction of the salary gap between Western/Northern and Southern European countries; developments in telecommunications and internet; the growing availability of low cost flights to Europe; and the effect of the periodic regularization programs conducted in Spain in 1986, 1991, 1996, 2000, 2001 and 2005 to 
provide legal status to some immigrants who resided in Spain without legal status (Fassmann and Münz, 1992; King et al., 1997; Hierro et al., 2013). ${ }^{3}$

Figure 1. International migration in Spain (1998-2010)

Not surprisingly, the burgeoning growth of the immigration phenomenon in Spain has come with notable changes in the composition by nationality of foreigners compared with past migration patterns. As portrayed in Table 1, until the late 1990s, it was Moroccan, British and German migration that dominated Spain's immigration scene; while Moroccan migration responded to Spain's demand for cheap labor in a favorable context of geographical proximity, the British and German communities were largely retirement-related seeking a warmer climate and high quality of life for their retirement years (King et al., 2000; De Haas, 2007; Gustafson, 2008). However, from 2001, the outstanding immigration from South American countries, mainly Ecuador and Colombia, and Romania reshaped the immigration landscape in Spain. In 2003 and for the first time, Ecuador relegated Morocco to the second rank, and in 2002 Colombia positioned itself as the country with the third highest number of nationals in Spain (Maza et al., 2013).

A new wave of immigration from Eastern Europe began after 2005. As also depicted in Table 1, in that year, Romania joined the list of countries that contribute the most to the number of foreigners who reside in Spain and took the third position in the rank of absolute numbers of immigrants. Perhaps more outstanding was that, with the share of immigration from Ecuador and Colombia declining, Romania was the country with the highest population in Spain from 2008 onward. Some factors, such as the decision to remove visa obligations for entering the

\footnotetext{
3 The total acceptance rate of regularization applications in Spain between 1986 and 2005 amounted to $74 \%$, which implies the concession of legal status to 1,100 thousand immigrants who resided in Spain without documentation.
} 
Schengen Space for Romanians in 2002, the right of free circulation (but not to work) after Romanian accession to the EU in January 2007, and the unlimited working rights for nationals from Romania since January 2009, fueled the extraordinary growth of this nationality in Spain (Viruela, 2011). ${ }^{4}$

Table 1. International migration in Spain: Main nationalities

Figure 2 provides a year-by-year picture of the provincial distribution of international migration (as percentage of total population) between 1998 and 2010. A glance at this figure reveals that, in the beginning of this period, international migration tended to cluster into areas characterized by high economic dynamism, such as the Mediterranean and South-Eastern coasts, the Ebro Valley, Madrid and its area of influence. Interestingly, only a few years later, what Hierro et al. (2013) defined as a process of positive contagion affecting provinces surrounded by highimmigration provinces, can be observed. In a nutshell, international migration spread from the east towards non-traditional destinations in the center of the country. Nevertheless, a significant degree of spatial concentration of immigrants in a few number of provinces continued to operate. This result, already found by other authors (e.g. Recaño, 2002; Recaño and Domingo, 2006), is in good agreement with some theoretical approaches to mobility and residence patterns of immigrants, as it is the case of the spatial assimilation theory (Preston et al., 1998; Bolt and van Kempen, 2010; Tammaru and Kontuly, 2011; Silvestre and Reher, 2014). According to this paradigm, newly arrived immigrants tend to first relocate in ethnic enclaves and accumulate social capital. Afterwards, both socio-economic advancement and acculturation of immigrants

\footnotetext{
${ }^{4}$ Like other EU countries, Spain decided to temporarily restrict the access of both Rumanians and Bulgarians to its internal labor market by placing a moratorium on labor movements until January 2014 at the latest. In 2009, the Spanish government decided to grant Romanian and Bulgarian workers the unrestricted right to work in Spain. However, high rates of unemployment and job destruction during the current recession forced the Spanish government to reestablish the moratorium in July 2011.
} 
in the host country enhance a process of residential segregation away from their initial settlement to suburban or very close territories.

Some researchers also highlight the role played by information spillover effects. That is the case of the study by Abrigo and Desierto (2011), who emphasize the effect of this kind of spillovers through geography-based migrant networks. According to these authors, as networks provide information not only to family members but also to neighbors, they reduce information asymmetries across provinces. Hierro et al. (2013) offer as additional possible explanations for immigrant dispersion geographic closeness, less-saturated labor markets and lower residential costs as other tentative explanations. As illustrated by various studies (see, for instance Viruela, 2011), the first waves of some nationalities, like Romanian and Bulgarian citizens, settled in a few provinces (mainly Madrid, Castellón and Almería) through social, familial and religious links. Their relatively high internal mobility explains their progressively higher presence in nearby locations, which in some cases, is due to much higher difficulties finding jobs and housing in some traditional destinations such as Madrid and to significant differences in work/residence permit processing times across provinces.

Figure 2. Distribution of Spain's international migration (\%) across provinces from 1998 to 2010

In sum, this set of figures exemplifies a clear-cut process of spatial redistribution of immigration over time in Spain and a new regional configuration for contemporary international migration that is unrelated to the current administrative regional landscape. It seems clear that immigration policies might best be carried out within a more homogenous regional configuration than the current administrative regional one. In the next section, we try to respond to this call by conducting an exploratory analysis that allows us to identify homogeneous and 
spatially contiguous areas of international migration and, by taking into account changes that occurred in the spatial shaping of immigration over the sample period, the potential existence of various "spatial regimes" that are stable over time.

\section{Main features of the spMorph}

Analytical regions, or spatial regimes, consist of spatially-contiguous areas that have a similar attribute. When the areas have similar spatio-temporal dynamics, the spatial regime can remain in force over time; however, in some cases, the spatial distribution of attributes can change sufficiently that the existing spatial regimes no longer provide a good representation of the spatial distribution of the attribute. In cases of significant spatial redistribution, spMorph comes into play and identifies the minimum number of sub-periods required (each with a different spatial regime), to guarantee a good representation of the major spatial patterns over time (Duque et al., 2014). An important feature of this tool for Exploratory Space-Time Data Analysis is that it incorporates the concepts of "Shock" and "Regime Fade": the Shock is the moment in which the spatial redistribution starts taking place, and the Regime Fade indicates the length of the transition period between one spatial regime and the next one. The Regime Fade seeks to incorporate realism into the solution, since spatial redistribution of socioeconomic variables usually does not occur instantaneously.

In spMorph, the level of intraregional similarity is measured with the Theil's inequality index, T, (Theil, 1972), which is a measure of inequality that ranges between 0 and $\log (\mathrm{n})$, with 0 indicating total equality and $\log (\mathrm{n})$ the total inequality. An important feature of this index is that it can be decomposed into two components: the inequality between regions $\left(\mathrm{T}_{b}\right)$ and the weighted average of inequality within regions $\left(\mathrm{T}_{W}\right)$, as follows:

$$
T=T_{b}+T_{w}=\sum_{\mathrm{k}=1}^{\mathrm{p}} \sum_{i \in k} \frac{X_{i}}{\sum_{i=1}^{n} X_{i}} \log \left(\frac{\mathrm{n}}{\mathrm{n}_{\mathrm{k}} \mathrm{s}_{\mathrm{k}}}\right)+\sum_{\mathrm{k}=1}^{\mathrm{p}}\left(\sum_{i \in k} \frac{X_{i}}{\sum_{i=1}^{n} X_{i}}\right) \sum_{\mathrm{i} \in \mathrm{k}} \mathrm{s}_{\mathrm{i}, \mathrm{k}} \log \left(\mathrm{n}_{\mathrm{k}} \mathrm{s}_{\mathrm{i}, \mathrm{k}}\right),
$$


where $n_{k}$ is the number of areas in region $k ; p$ is the number of regions in the regime, $n$ is the total number of areas $\left(n=\sum_{k} n_{k}\right) ; s_{k}=\sum_{i \in k} X_{i} / \sum_{i=1}^{n} X_{i}$ is the share of attribute $\mathrm{X}$ accounted by region $k$; and $s_{i, k}=X_{i, k} / \sum_{i=1}^{n_{k}} X_{i, k}$ is the share of attribute $\mathrm{X}$ in region $\mathrm{k}$ accounted by area $i$ (Duque et al., 2014).

The heuristic process in spMorph identifies both the sub-periods and the regimes that minimize the area below the lower bound of the functions that result from calculating the ratio $T_{w} / T$ for each year and each regime. Finally, the Regime Fade is calculated a posteriori as the time between the shock and the moment in which the functions $T_{w} / T$, calculated for the regimes before and after the shock, intersect.

In summary, the spMorph is a new tool for Exploratory Space-Time Data Analysis that allows practitioners to identify elements such as "Shock", "Regimes" and "Regime Fade" in an easy and intuitive fashion. It also allows making new lectures of spatio-temporal dynamics that, from the best of our knowledge, are not easy to replicate with other techniques in the literature.

\section{Empirical analysis with spMorph}

We first compare the six official regions (NUTS I regions) with analytical regions that result from the aggregation of provinces that share similar dynamics over the period of 1998-2010. Following the original formulation of the spMorph, we used the p-regions model, devised by Duque et al. (2011), to design six analytical regions. The p-regions permits the aggregation of provinces into $p=6$ spatially contiguous regions each of which shows a high degree of similarity in the relative share of international migration. The p-regions offers two advantages compared to other methods for designing analytical regions: First, it is formulated as a mixed integer-linear programing model, which guarantee that it is possible to find an optimal solution. 
Second, it imposes the spatial contiguity constraint without making any assumption on the shape of the analytical regions (other methods in the literature reach spatial contiguity by enforcing compactness, which prevents the design of analytical regions that follow non-compact spatial patterns). ${ }^{5}$ Figure 3 presents both the six NUTS I regions and the six analytical p-regions that summarize the migration stocks between 1998 and 2010. The areas are shaded according to the international migration stock in 2010. As we can clearly observe, the traditional NUTS I grouping of Spanish provinces does not appear to reflect the contemporary international migration patterns in Spain. On the contrary, mapping based on the analytical regions criteria seems to provide a more reliable picture of the real dynamics of international migration in Spain: three areas that group the Mediterranean and South-East provinces in Spain, display high levels of immigration, and reflect the most incipient stage of international migration in the country; two areas made up of provinces located in the Center-East of the country and reflect areas of recent reception of international migration; and one area that comprises a group of North-West provinces where immigrants' presence can currently be considered negligible.

Figure 3. Official NUTS I regions (left) vs. analytical regions (right) for the period 1998-2010

To provide further confirmation of this result, Figure 4 shows the inequality within regions $\left(T_{W}\right)$ as a percentage of the total inequality $(T)$ when using the official and analytical regions. As regards its interpretation, a good spatial regime will keep the ratio low every period, which implies a high level of homogeneity within each region. The share of intraregional inequality is remarkably lower for the analytical than for the official regions. Specifically, while the inequality within regions represents an average of $40.53 \%$ of the total inequality for the official regions, this percentage is only $15.79 \%$ for the analytical regions. This result lends clear support

\footnotetext{
${ }^{5}$ See Gordon (1999), Duque et al. (2006), Duque et al. (2007), Duque et al. (2012) for other methods to design analytical regions.
} 
to our argument that analytical regions provide a more reliable picture of the real dynamics of international migration in Spain than the traditional grouping.

Figure 4. Inequality within regions $(T w)$ as a percentage of total inequality $(T)$

We cannot overlook the fact that the share of intraregional inequality at the beginning is roughly three times as high as at the end of the sample period. This seems to indicate that the capacity of the analytical regions to aggregate the areas into homogenous regions is much higher since 2004 and, in consequence, that a proper representation of the spatiotemporal dynamics of international migration in Spain requires more than the single spatial regime presented in Figure 3. To explore this possibility, we next apply the spMorph algorithm proposed by Duque et al. (2014). The essence of this algorithm is to aggregate areas into regions such that a measure of intraregional heterogeneity is minimized. Following Gordon (1999), we define this intraregional heterogeneity as the within-cluster sum of squared Euclidean distances from each area to the attribute centroid of its cluster. In our case, each province has thirteen attributes that correspond to the percentage of international migration from 1998 to 2010 .

Figure 5 presents the lower bounds obtained for various numbers of shocks. The lower bound labeled ' 0 ' corresponds to the case where there is no shock, which implies the existence of a single spatial regime for the whole sample period; as can be observed, this is the case previously depicted in Figure 3. In addition, we consider that the period can be exposed to at most 12 shocks. Although this extreme case is not possible in practice, it provides information about the minimum level that the Total Lower Bound can reach; this is addressed later. It is also worth noting that when considering one shock over the sample period, the lower bound displays significantly lower values until 2004 and maintains the same trend then after. In sum, this result gives support to the idea that at least one shock has occurred in the spatial distribution. 
Figure 5. Lower bound for various numbers of shocks

At this point, an important decision must be made about the choice of the actual number of shocks that best represents the spatiotemporal dynamics of Spain's international migration. Although not denying the subjectivity of this decision, Duque et al. (2014) recommend choosing the minimum number of shocks that generate the largest improvement in the lower bound. The key idea is to gain appropriate knowledge about general trends. As guidance criteria to choose an adequate number of shocks, Figure 6 presents the values for the Total Lower Bound (TLB). According to Duque et al. (2014), this element represents the area below the lower bound and can be used to compare solutions that place the shock in various years; the lower the TLB, the better the choice of the number of shocks. A glance at this figure reveals that splitting the sample period into three sub-periods (two shocks) contributes significantly to the reduction of intraregional inequality, and the marginal contribution of considering additional sub-periods (three or more shocks) is virtually negligible.

Figure 6. Total Lower Bound (TLB) for various numbers of shocks

Then, we proceed by analyzing the case of two shocks in the spatial distribution. When running the spMorph algorithm for two shocks, we obtain that the first shock occurred in 2000 and the second one in 2003. This allows us to split the sample period into the three following spatial regimes: 1998-2000, 2001-2003, and 2004-2010. Figure 7 depicts the regional configuration of each spatial regime. These mappings perfectly reproduce the various phases that the international migration in Spain has been through since the late 1990s: a first phase of incipient immigration clustered mainly in the Mediterranean coast and Madrid; a second phase of massive immigration spread its influence from east to west; and a phase of steady growth due to Eastern Europe immigration that was more moderate since the eruption of the current economic 
crisis. According to Reher et al. (2011), despite job destruction for immigrants already taking place since 2008, the foreign-born population levels were still increasing, albeit very slightly, as the adjustment between job demand and supply was neither perfect neither instantaneous. Put another way, although it seems clear that the phase of massive immigration to Spain, which began in the early 2000s, has come to an end (due, mainly, to large job destruction, especially in low value-added economic sectors with traditionally high-demand of unskilled migrant workers), the recent economic recession has not had a sudden drop in the number of immigrant stocks.

Figure 7. Spatial regimes obtained by solving the max-p-regions model for the sub-periods

As previously indicated, the algorithm also allows us to disentangle the time taken for each shock to generate a spatial redistribution of the variable that results in a new spatial regime (i.e., regime fade). This can be inferred from Figure 8, which compares the evolution of the share of intraregional inequality $\left(T_{w} / T\right)$ generated for each spatial regime. Specifically, the regime fade corresponds to the time between a shock and the emergence of a new spatial regime (point at which the $T_{w}$ lines cross). A close look at the figure reveals that the transition to the second regime takes place almost immediately after the first shock in 2000 , just coinciding with the international migration takeoff in Spain. The transition to the third spatial regime is a bit slower and takes one year for the shock in 2003 to result in a new spatial regime; it may be significant that around that year the introduction of visa requirements for nationals coming from Ecuador and Colombia took place to prevent the arrival of massive undocumented immigration to Spain and to comply with European Union regulations. This result evidences the rapid nature of the changes in the spatial distribution of international migration across Spanish provinces and the need to follow the evolution of the distribution and particularly the emerging of new spatial regimes over time more closely. 
Figure 8. Inequality within regions $(T w)$ as a percentage of total inequality $(T)$

\section{Conclusions}

This paper examines the spatial distribution of international migration across the Spanish provinces over the period of 1998-2010 using a novel tool for exploratory space-time data analysis called spMorph. In addition to the possibility of offering a new way to analyze immigration in Spain, this methodology exposes a potential new dimension of the ecological fallacy problem: spatial aggregation causes a loss of information (which is minimized though the use of analytical regions), but, when a variable experiences important spatial redistributions over time, an important amount of information can be lost when it is assumed that the whole process can be summarized with a unique spatial regime.

The results of the analysis showed that administrative regions do not provide a reliable picture of the real dynamics in Spain's international migration distribution in so far as the areas within it show no similar migration patterns. The analytical regions identified in this paper, which have a clear east-west pattern, provided a better representation of the migration dynamics in Spain compared with the official regions. In addition, the identification of two spatial shocks revealed the existence of three spatial regimes that consistently characterize the various phases that international migration has been through since the late 1990s. The first regime, from 1998 to 2000, highlights the two main destinations of immigrants at the beginning of the immigration wave: the Mediterranean coast and Madrid. The second regime, from 2001 to 2003, captures the fast transition toward a spreading process with an east-west pattern. A smooth transition towards a third regime, from 2004 to 2010, captures the steady growth due to Eastern European immigration. 
The results of the analysis are not devoid of policy implications. On the whole, they cast some doubt on the outcomes that can be expected of regional immigration policies designed at the level of official regions. It has to be pointed out that since the extension of regional governments' competences (stipulated in the "statutes of autonomy') and the revision of regional financing, competences of the Spanish central government regarding immigration are mainly restricted to the management and control of immigration flows (nationality, work and residence permits, political asylum, control of national borders) while the Spanish regions (in collaboration with local governments) assume the responsibility for immigrants' integration (including social services, education, health, housing, cultural initiatives and labor promotion) through the design of integration plans for immigrants. Roughly speaking, two main inefficiencies may arise directly from the enforcement of immigration policies over spatially heterogeneous areas: first, those pertaining to the use of more scarce resources to carry out policies, which is a topic that should be part of policy actions in the current context of the economic downturn; and second, those that arise from a mismatch between policy targets and the real needs of regions. In consequence, the results seem to enforce the idea that a shift in spatial policy scale from official to analytical regions might offer an opportunity to improve policy effectiveness on the grounds of international migration with the confidence that the provinces within the regions will have a similar response to the policy. Undoubtedly, this policy recommendation is not devoid of costs. The reorientation of immigrant policies from official to analytical regions would imply not only a change of policy objectives, but also the creation of new institutions and transaction costs, for which additional resources and closer cooperation between social and institutional actors would be required. It seems reasonable, therefore, that the gains and costs of the aforementioned institutional adjustment are assessed carefully against the outcomes from the existing framework and that, whatever the outcome, the analytical region approach can be used as a support tool with the intention of contributing and assisting in decision-making processes related to immigration issues. 
Finally, future research can move from exploratory to causal analysis to see if the results about the shocks in 2000 and 2003 detected with spMorph can be understood as structural breaks within the context of panel data econometric models. Thus, it would be interesting to compare spMorph with econometric-based methods for structural breaks identification such the Chow Test (chow 1960), the Quandt Test (Quandt, 1960), or the Bai-Perron (Bai and Perron, 1998).

\section{References}

Abrigo, M.R.M., Desierto, D.A. (2011). Contagious migration: Evidence from the Philippines. Discussion paper series No. 2011-18, Philippine Institute for Development Studies.

Arango, J. (2003). Europa, ¿una sociedad multicultural en el siglo XXI? Papeles de Economía Española, 98: 2-15.

Bai, J., Perron, P. (1998). Estimating and testing linear models with multiple structural changes. Econometrica, 66:47-78.

Bolt, G., van Kempen, R. (2012). Ethnic segregation and residential mobility: Relocations of minority ethnic groups in the Netherlands. Journal of Ethnic and Migration Studies, 36(2): 333-354.

Bover, O., Velilla, P. (2002). Migrations in Spain: Historical Background and Current Trend. In: Zimmermann K. (ed.), European Migration: What Do We Know? CEPR and Oxford University Press.

Carella, M., Pace, R. (2001). Some migration dynamics specific to southern Europe: south-north and east-west axis. International Migration, 39(4): 63-99.

Carling, J. (2007). Unauthorized migration from Africa to Spain. International Migration, 45(4): 3-37.

Chow, G.C. (1960). Tests of equality between sets of coefficients in two linear regressions. Econometrica 28:591-605.

Collantes, F., Pinilla, V., Sáez, L.A., Silvestre, J. (2014). Reducing depopulation in rural Spain: The impact of immigration. Population, Space and Place, 20(7): 606-621. 
Dall'erba, S., Guo, D. (2009). Structure of Interregional Migration Flows in Spain: 1998-2006. Ensayos sobre Politica Economica, 27(58): 264-276.

De Haas, H. (2007). Morocco's migration experience: a transitional perspective. International Migration, 45(4): 39-70.

Duque, J.C., Anselín, L., Rey, S.J. (2012). The Max-p-Regions problem. Journal of Regional Science, 52(3): 397-419.

Duque, J.C., Artís, M., Ramos, R. (2006). The ecological fallacy in a time series context: Evidence from Spanish regional unemployment rates. Journal of Geographical Systems 8(4): 391-410.

Duque, J.C., Church, R.L., Middleton, R.S. (2011). The p-regions problem. Geographical Analysis, 43: 104-126.

Duque, J.C., Ramos, R., Surinach, J. (2007). Supervised regionalization methods: A survey. International Regional Science Review, 30(3):195-220.

Duque, J.C., Ye, X., Folch, D.C. (2014). spMorph: An exploratory space-time analysis tool for describing processes of spatial redistribution. Papers in Regional Science (DOI: 10.1111/pirs.12088).

Fassmann, H., R. Munz, R. (1992). Patterns and trends of international migration in Western Europe, Population and Development Review, 18(3): 457-480.

Fernández, C., Ortega, C. (2008). Labor market assimilation of immigrants in Spain: employment at the expense of bad job-matches? Spanish Economic Review, 10(2): 83107.

Finotelli, C., Arango, J. (2011). Regularisation of unauthorised immigrants in Italy and Spain: determinants and effects. Documents d'anàlisi geogràfica, 57(3), 495-515.

Gordon, A.D. (1999). Classification, $2^{\text {nd }}$ edn. Chapman \& Hall, Boca Raton.

Gustafson, P. (2008). Transnationalism in retirement migration: The case of North European retirees in Spain. Ethnic and Racial Studies, 31(3): 451-475. 
Hierro, M. (2016). Latin American Migration to Spain: Main reasons and future perspectives. International Migration, 54(1), 64-83.

Hierro, M., Maza, A. (2010a) Per capita income convergence and internal migration in Spain: Are foreign-born migrants playing an important role? Papers in Regional Science, 89: 89-107.

Hierro, M., Maza, A. (2010b). Foreign-born internal migrants: Are they playing a different role than natives on income convergence in Spain? Applied Geography, 30(4): 618-628.

Hierro, M., Maza, A., Villaverde, J. (2013). A proposal for detecting spatial contagion: Some evidence on the international migration distribution in Spain. Papers in Regional Science, 92(4): 811-829.

Huntoon, L. (1998). Immigration to Spain: implications for a unified European Union immigration policy. International Migration Review, 32(2): 423-450.

Izquierdo, A. (1996). La inmigración inesperada. Trotta, Madrid.

Izquierdo, A., Carrasco, C. (2005). Flujos y tendencias y signos de instalación de los extranjeros en España. Papeles de Economía Española, 104: 92-122.

King, R., Fielding, A.J., Black, R. (1997). The international migration turnaround in Southern Europe. In: King R., Black R. (eds.), Southern Europe and the new immigrations. Sussex Academic Press, Brighton.

King, R., Warnes, A.M., Williams, A.M. (2000). Sunset lives. British retirement migration to the Mediterranean, Berg Publishers, Oxford.

Maza, A., Villaverde, J., Hierro, M. (2013). Explaining the settlement patterns of foreigners in Spain. Applied Geography, 40: 11-20.

Neubecker, N., Smolka, M. (2013). Co-national and cross-national pulls in international migration to Spain. International Review of Economics and Finance, 28: 51-61.

Peixoto, J., Arango, J., Bonifazi, C., Finotelli, C., Sabino, C., Strozza, S. Triandafyllidou, A. (2012). Immigrants, markets and policies in Southern Europe. In: Okólski M. (ed.), 
European Immigration: Trends, Structures and Policy Implications. IMISCOE Research. Amsterdam University Press.

Preston, V., McLafferty, S., Liu, X.F. (1998). Geographical barriers to employment for American-born and immigrant workers. Urban Studies, 35(3), 529-545.

Quandt, R.E. (1960). Tests of the hypothesis that a linear regression system obeys two separate regimes. Journal of the American Statistical Association 55:324-330.

Recaño, J. (2002). La movilidad geográfica de la población extranjera en España: un fenómeno emergente. Cuadernos de Geografía, 72: 135-156.

Recaño, J., Domingo, A. (2006). Evolución de la distribución territorial y la movilidad geográfica de la población extranjera en España. In: Aja E, Arango J (eds.), Veinte años de inmigración en España. Perspectivas jurídica y sociológica (1985-2000). Fundación CIDOB, Barcelona.

Reher, D., Requena, M., Sanz, A. (2011). ¿España en la encrucijada? Consideraciones sobre el cambio de ciclo migratorio. Revista Internacional de Sociología, 69(M1), 9-44.

Reher D., Silvestre J. (2009). Internal migration patterns of foreign-born immigrants in a country of recent mass immigration: Evidence from new micro data for Spain. International Migration Review, 43(4); 815-849.

Reher D., Silvestre J. (2014). The internal migration of immigrants: Differences between onetime and multiple movers in Spain. Population, Space and Place, 20: 50-65.

Tammaru, T., Kontuly, T. (2011). Selectivity and destinations of ethnic minorities leaving the main gateway cities of Estonia. Population, Space and Place, 17, 674-688.

Theil, H. (1972). Statistical decomposition analysis. Amsterdam, North Holland.

Viruela, R. (2011). The Romanian migrants in Spain. An exceptional migratory flow. International Review of Social Research, 1: 31-59.

Zorlu, A., Mulder, C. (2008). Initial and subsequent location choices of immigrants to the Netherlands. Regional Studies, 42(2): 245-264. 
Table 1. International migration in Spain: Main nationalities

\begin{tabular}{llcclccccc}
\hline & \multicolumn{3}{c}{$\mathbf{1}^{\mathbf{0}}$ Nationality } & \multicolumn{3}{c}{$\mathbf{2}^{\mathbf{0}}$ Nationality } & \multicolumn{3}{c}{$\mathbf{3}^{\mathbf{0}}$ Nationality } \\
\cline { 2 - 10 } & Country & $\begin{array}{c}\text { Population } \\
\text { (thousands) }\end{array}$ & $\%$ & Country & $\begin{array}{r}\text { Population } \\
\text { (thousands) }\end{array}$ & $\%$ & Country & $\begin{array}{r}\text { Population } \\
\text { (thousands) }\end{array}$ & $\%$ \\
\hline 1998 & Morocco & 111 & 17.4 & UK & 76 & 11.9 & Germany & 60 & 9.5 \\
1999 & Morocco & 133 & 17.8 & UK & 89 & 11.9 & Germany & 76 & 10.1 \\
2000 & Morocco & 173 & 18.7 & UK & 99 & 10.7 & Germany & 89 & 9.6 \\
2001 & Morocco & 233 & 17.0 & Ecuador & 139 & 10.1 & UK & 107 & 7.8 \\
2002 & Morocco & 307 & 15.5 & Ecuador & 260 & 13.1 & Colombia & 191 & 9.7 \\
2003 & Ecuador & 390 & 14.6 & Morocco & 379 & 14.2 & Colombia & 245 & 9.2 \\
2004 & Ecuador & 476 & 15.7 & Morocco & 421 & 13.9 & Colombia & 249 & 8.2 \\
2005 & Morocco & 511 & 13.7 & Ecuador & 498 & 13.3 & Romania & 317 & 8.5 \\
2006 & Morocco & 563 & 13.6 & Ecuador & 461 & 11.1 & Romania & 407 & 9.8 \\
2007 & Morocco & 583 & 12.9 & Romania & 527 & 11.7 & Ecuador & 427 & 9.5 \\
2008 & Romania & 732 & 13.9 & Morocco & 653 & 12.4 & Ecuador & 428 & 8.1 \\
2009 & Romania & 799 & 14.1 & Morocco & 718 & 12.7 & Ecuador & 421 & 7.5 \\
2010 & Romania & 831 & 14.5 & Morocco & 754 & 13.1 & Ecuador & 400 & 7.0 \\
\hline
\end{tabular}


1

2

3

4

5

6

7

8

9

10

11

12

13

14

15

16

17

18

19

20

21

22

23

24

25

26

27

28

29

30

31

32

33

34

35

36

37

38

39

40

41

42

43

44

45

46

47

48

49

50

51

52

53

54

55

56

57

58

59

60

Figure 1. International migration in Spain (1998-2010)

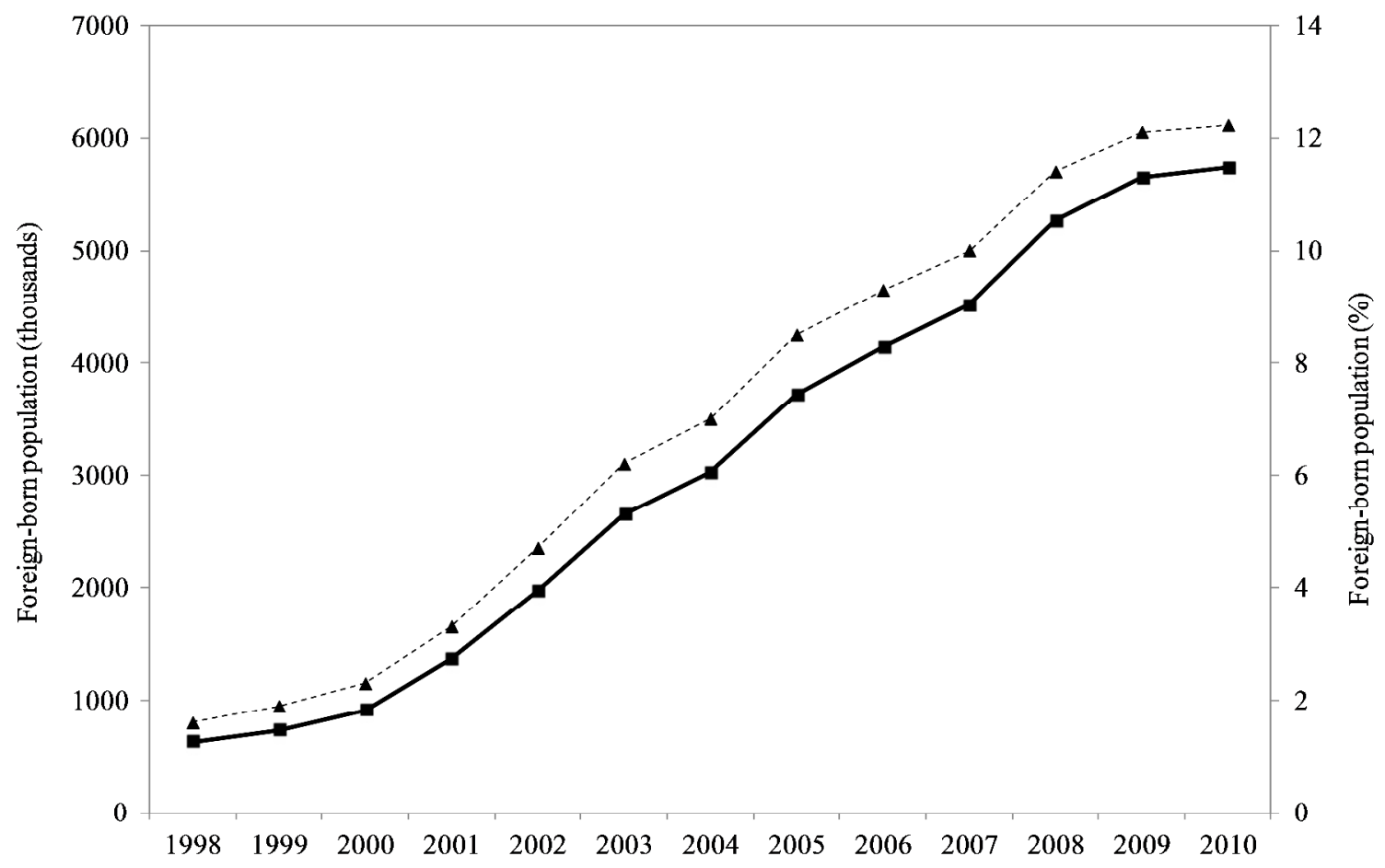


Figure 2. Spain's international migration (\%) across provinces from 1998 to 2010
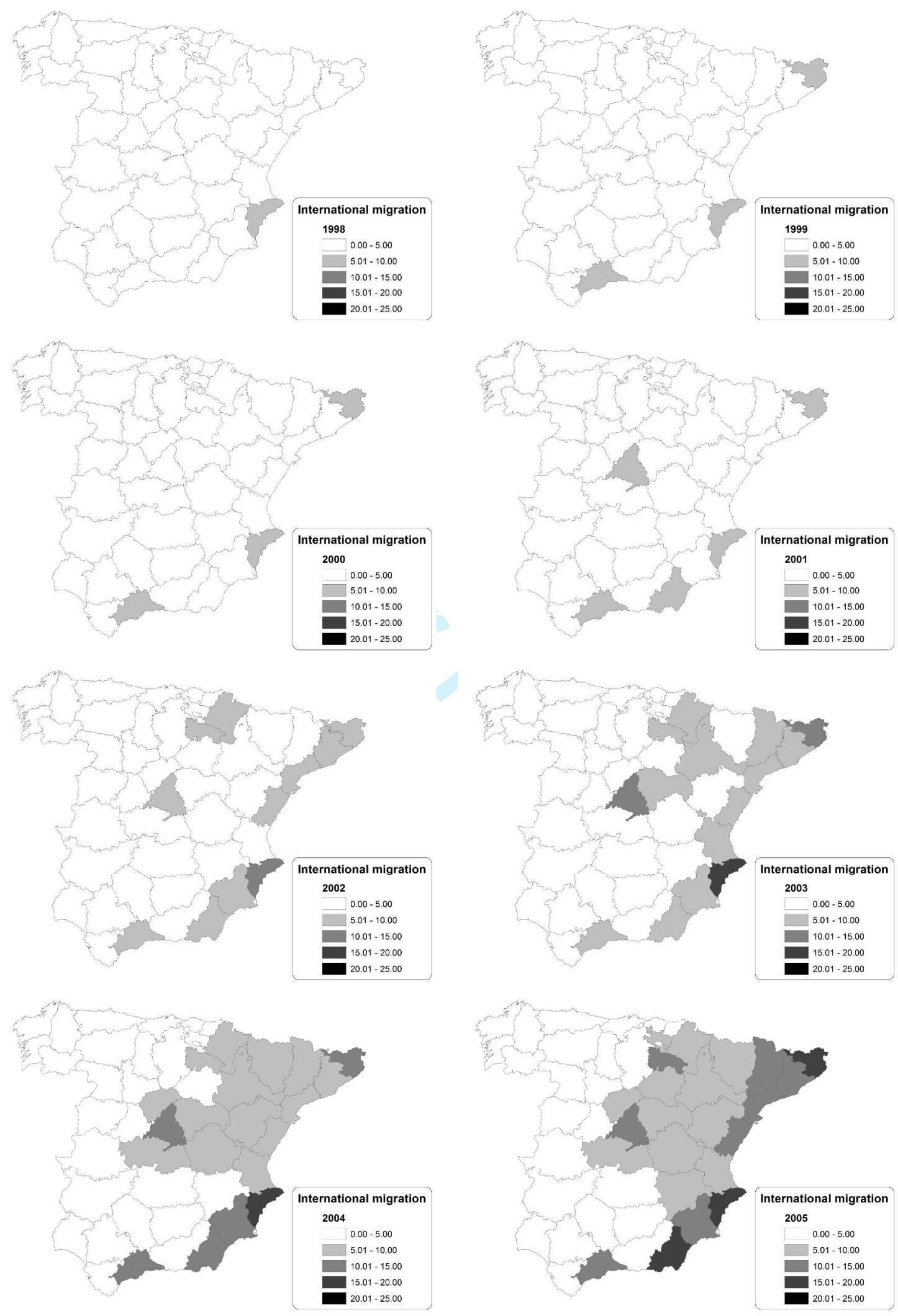

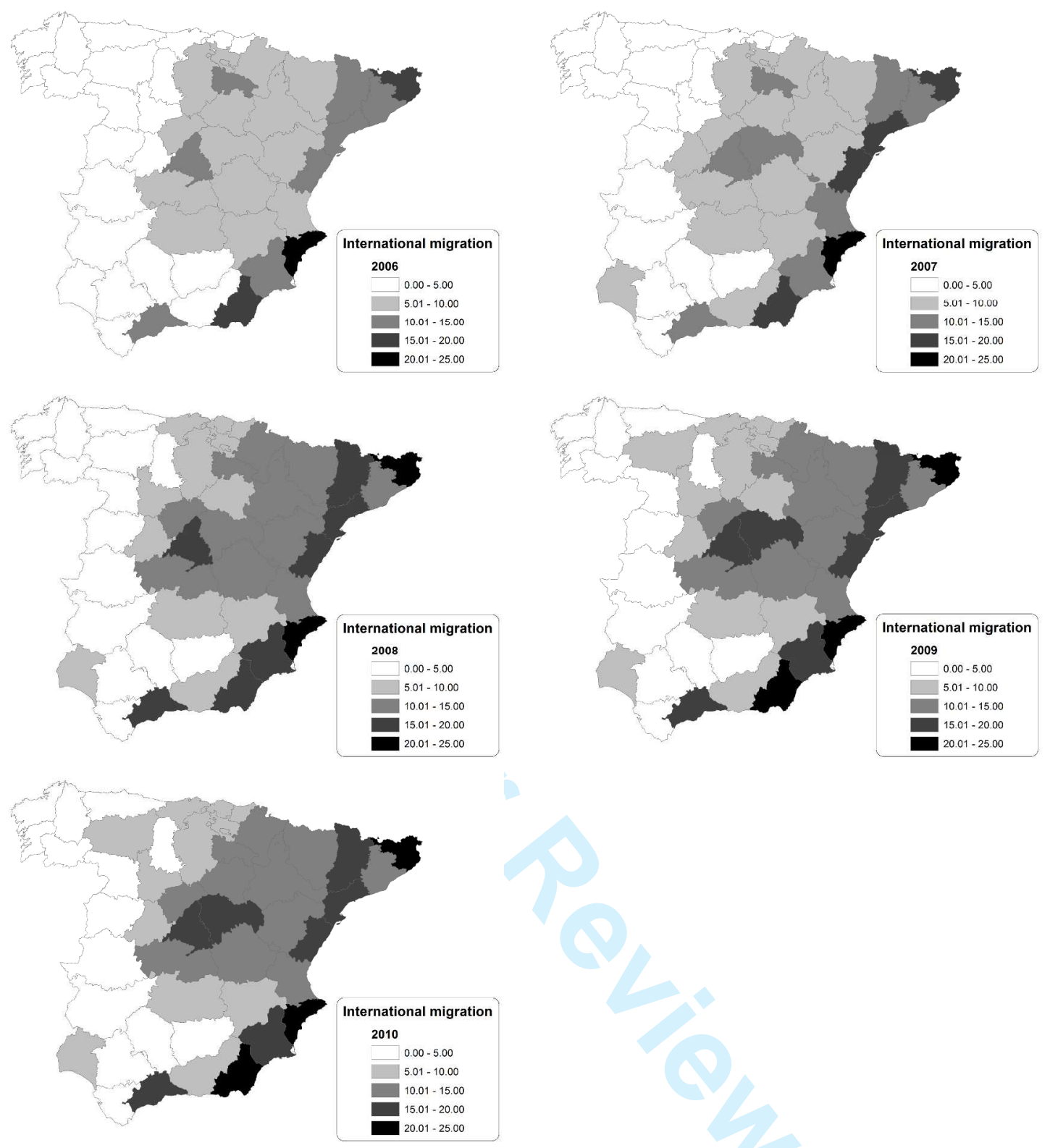

8

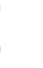

7.

0

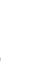

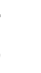

.
.

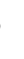
5 (n) . . . . . . . 
International Migration

Page 26 of 31

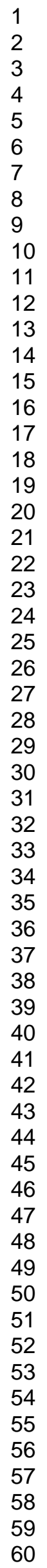

Figure 3. Official NUTS I regions (left) vs. analytical regions (right) for the period 1998-2010
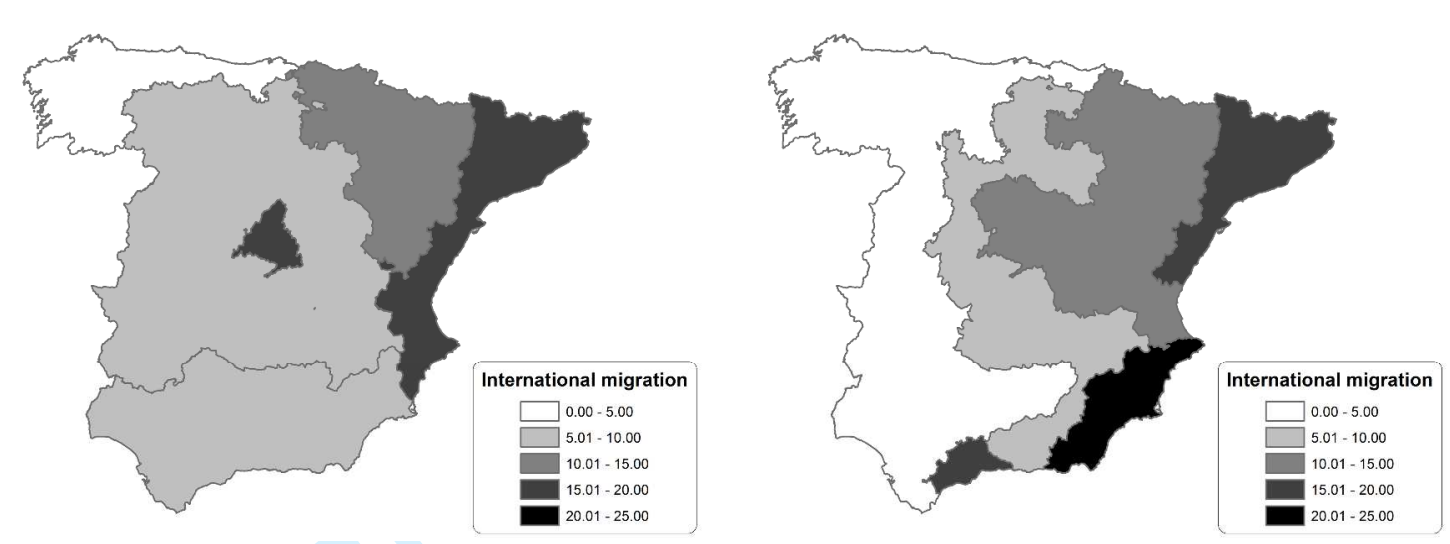
Figure 4. Inequality within regions $(T w)$ as a percentage of total inequality $(T)$

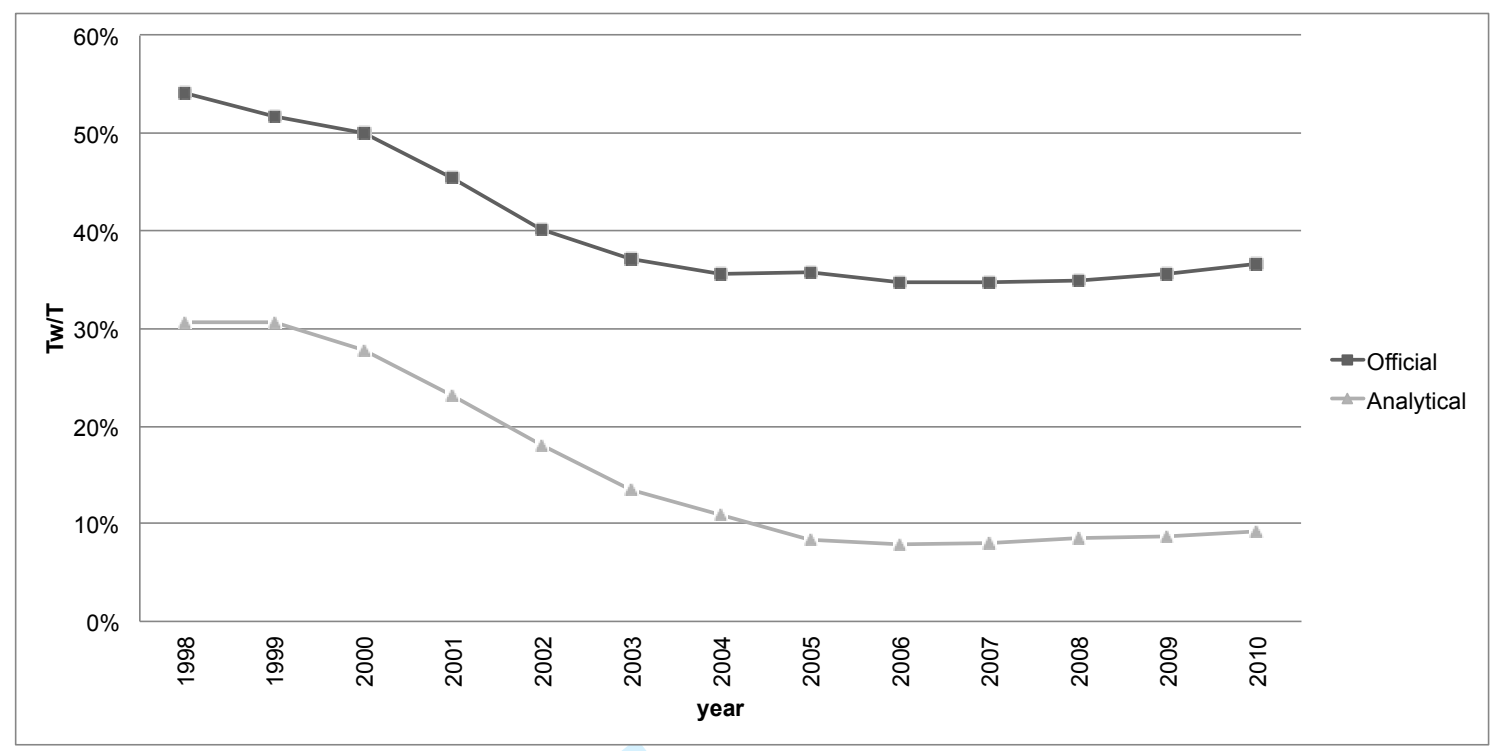

1

2

4

5

6

7

8

9

10

11

12

14

15

16

17

18

19

20

21

22

23

24

25

26

27

28

29

30

31

32

33

34

35

36

37

38

39

40

41

42

43

44

45

46

47

48

49

50

51

52

53

54

55

56

57

58

59

60 
Figure 5. Lower bound for various numbers of shocks

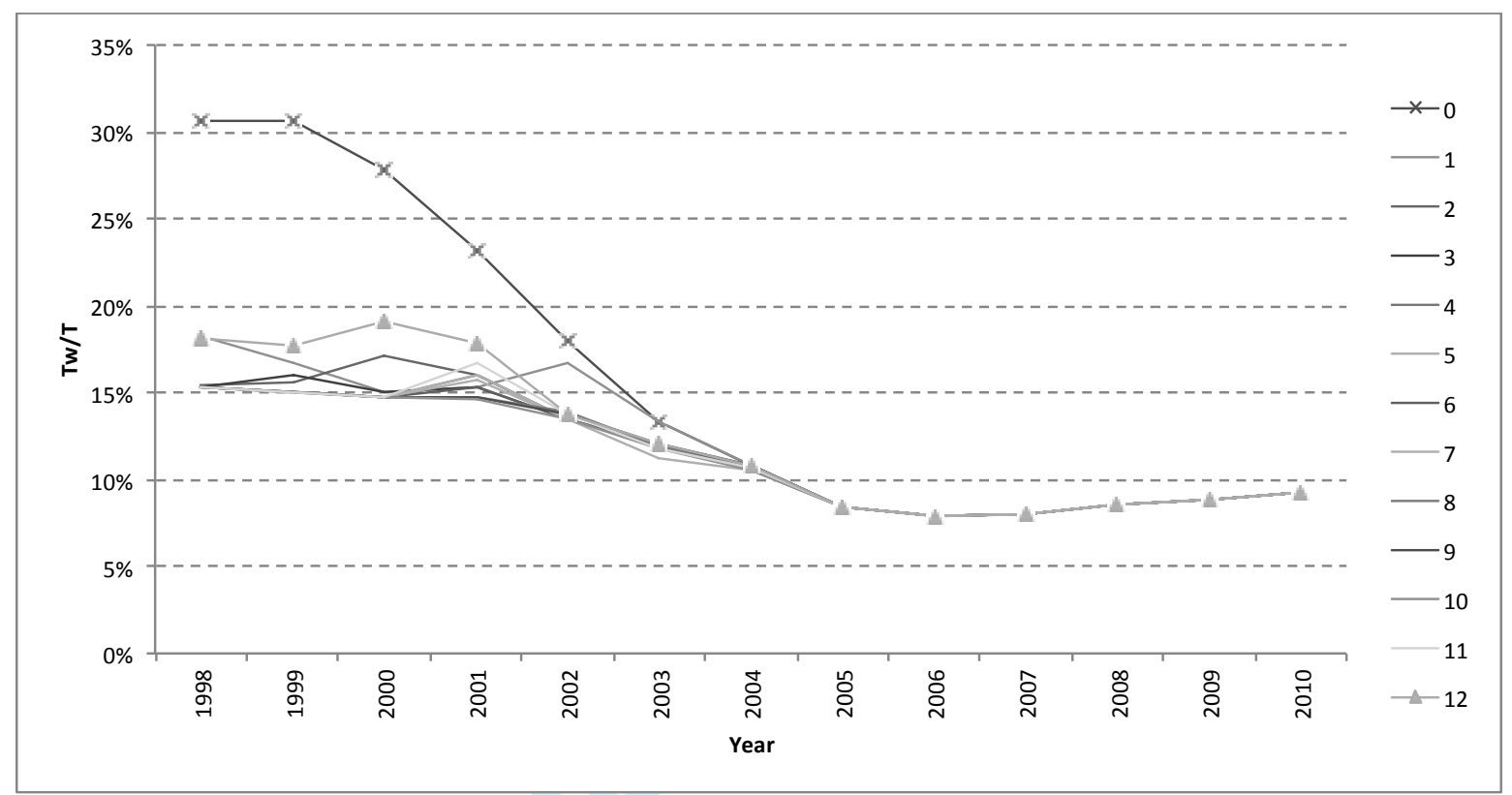


Figure 6. Total Lower Bound (TLB) for various numbers of shocks

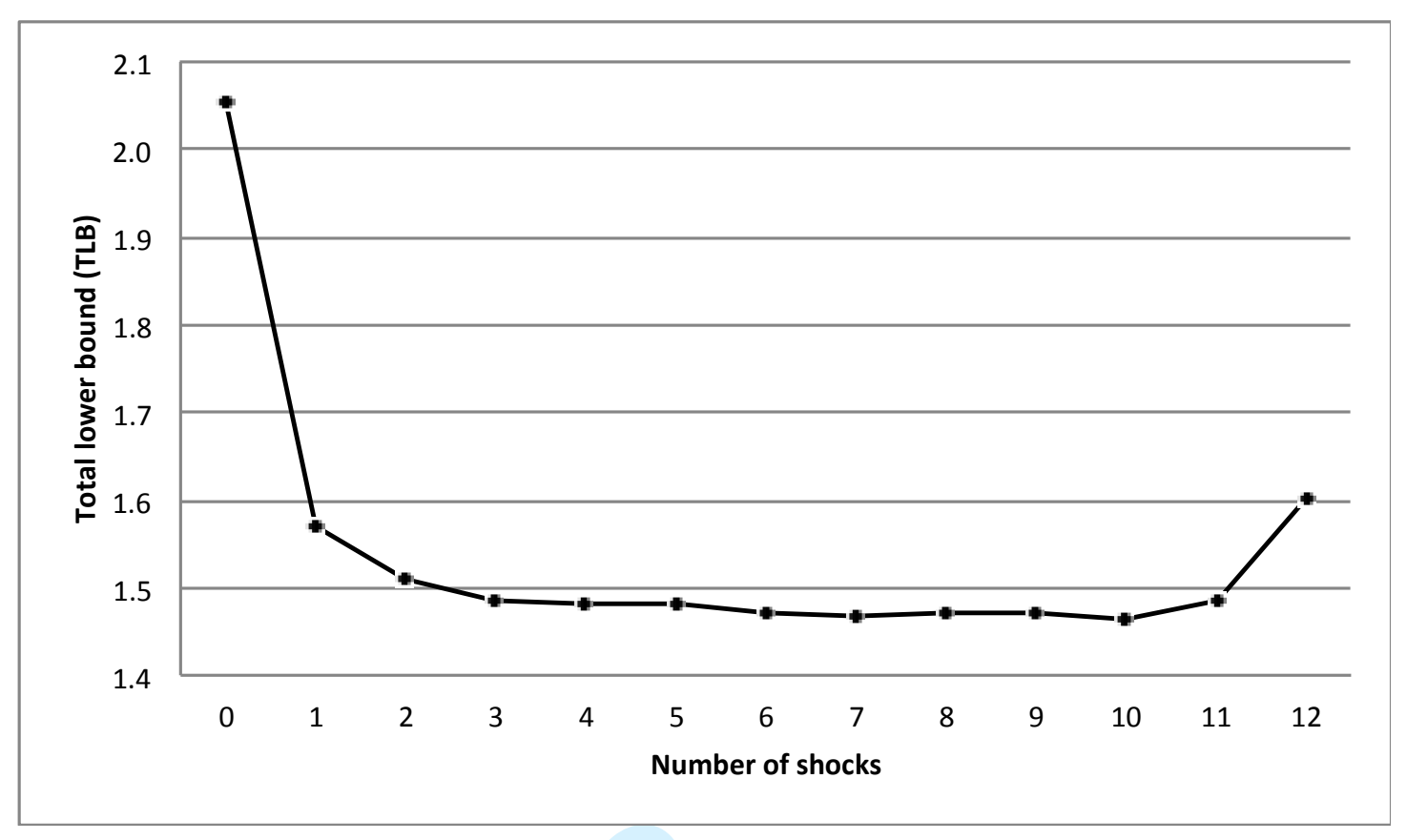

1

2

4

5

6

7

10

11

12

13

14

15
16

17

18

19

20

21

22

23

24

25

26

27

28

29

30

31

32

33

34

35

36

37

38

39

40

41

42

43

44

45

46

47

48

49

50

51

52

53

54

55

56

57

58

59

60 
Figure 7. Spatial regimes obtained by solving the max-p-regions model for the sub-periods

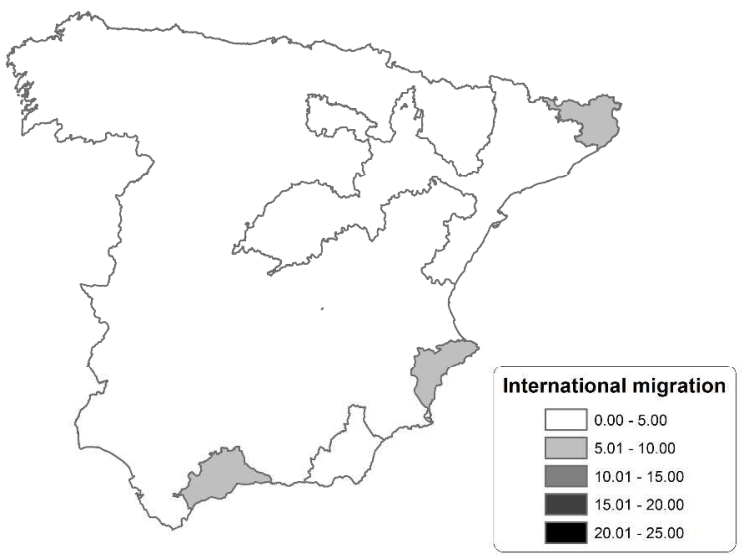

(a) Regime 1998-2000

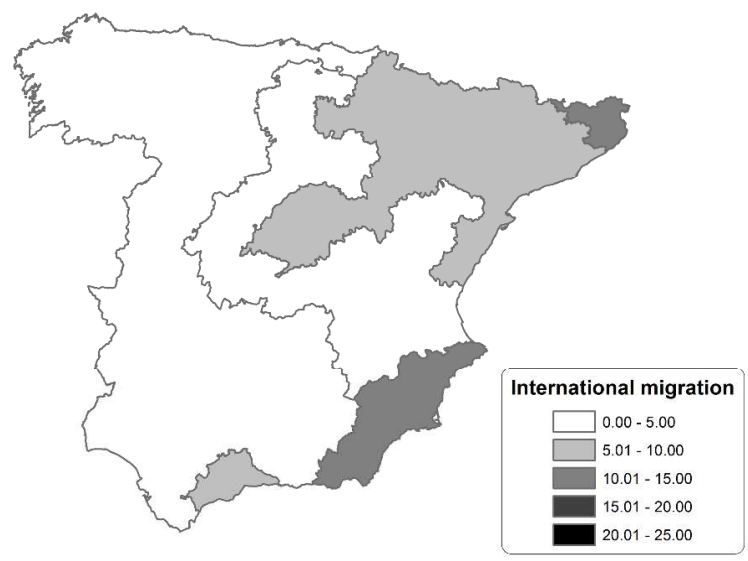

(b) Regime 2001-2003

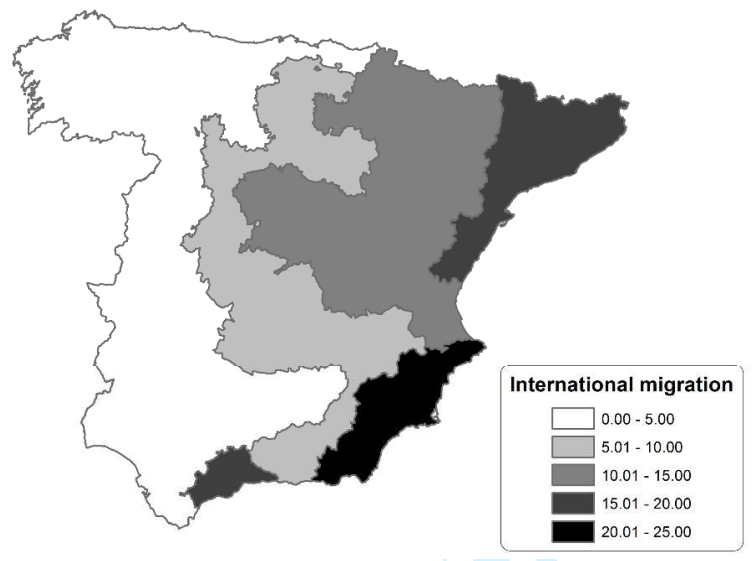

(c) Regime 2004-2010 
Figure 8. Inequality within regions $(T w)$ as a percentage of total inequality $(T)$

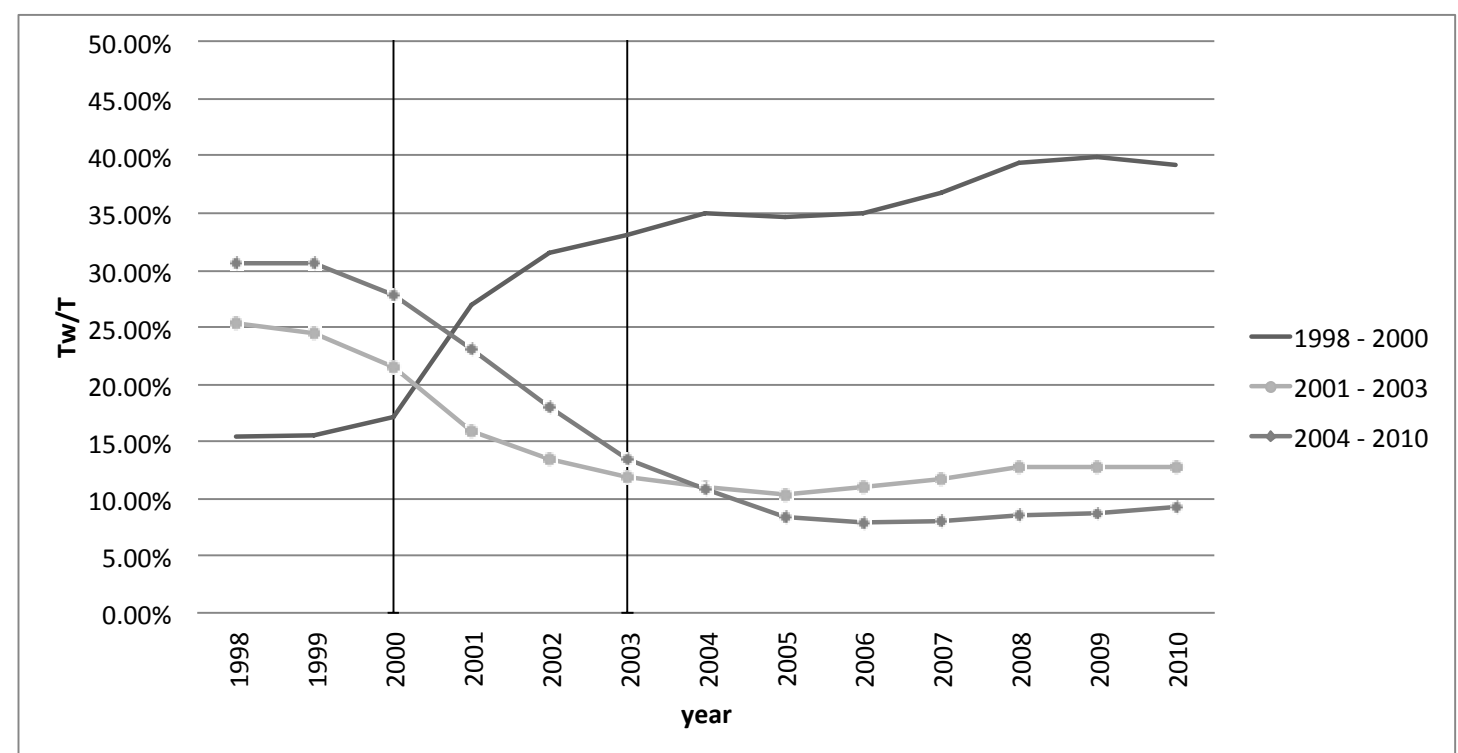

